\title{
Desafios na Transferência de Tecnologia Universidade-Empresa: um relato de experiência do Núcleo de Transferência de Tecnologia da UFRB
}

\section{Challenges in University-Industry Transfer of Technology: a case report of the experience by the Technology Transfer Nucleus of UFRB}

\author{
Gustavo Modesto Amorim ${ }^{1}$ \\ Edilson Araújo Pires ${ }^{1}$ \\ Ferlando Lima Santos ${ }^{2}$ \\ ${ }^{1}$ Universidade Federal do Recôncavo da Bahia, Cruz das Almas, BA, Brasil \\ ${ }^{2}$ Universidade Federal do Recôncavo da Bahia, Santo Antonio de Jesus, BA, Brasil
}

\begin{abstract}
Resumo
O processo de Transferência de Tecnologia e a relação Universidade-Empresa (TTUE) têm sido discutidos no Brasil com grande frequência nos últimos anos. Apesar dos avanços promovidos pela Lei n. 10.973/2004 e Lei n. 13.243/2016, uma diversidade de barreiras na promoção da TTUE é comum nas Instituições de Ciência, Tecnologia e Inovação do país. Esse artigo apresenta um relato de experiência da utilização de estratégias para tornar uma tecnologia desenvolvida pela universidade em uma inovação mercadológica, ou seja, promover a TTUE. A partir da descrição das ações do Núcleo de Transferência de Tecnologia e Captação de Recursos da Universidade Federal do Recôncavo da Bahia (UFRB) e do grupo de Bioprodutos e Processos Aplicados à Nutrição Humana da UFRB para colocar uma tecnologia patenteada no mercado, discutiu-se essas ações correlacionando-as à prática e debatendoas com base na literatura científica que discorre sobre as estratégicas que podem ser adotadas para ascender ao mercado um produto inovador com potencial mercadológico.
\end{abstract}

Palavras-chave: Transferência de Tecnologia. Universidade-Empresa. Inovação.

\begin{abstract}
The process of University-Industry Technology Transfer (UITT) has been discussed in Brazil with great frequency in recent years. Despite advances promoted by Laws 10973/2004 and 13243/2016, a variety of barriers to the promote UITT is similarly found in Brazilian Institutions of Science, Technology and Innovation. This article presents a case report of the usage of strategic management techniques applied to a technological product developed by the university which aims its insertion into market through UITT. Based on the efforts to put a patented technology into the market by the Nucleus of Transfer of Technology and Funding of the Federal University of the Recôncavo of Bahia (UFRB) and of the group of Bioproducts and Processes Applied to Human Nutrition of the UFRB, many actions are described, correlating them to practice and debating them based on the scientific literature in which discusses the strategies that can be adopted to promote an innovative product with market potential.
\end{abstract}

Keywords: University-Industry Technology Transfer. Innovative product. Technological product

Área Tecnológica: Saúde. Transferência de Tecnologia. 


\section{Introdução}

No Brasil, principalmente a partir do início do século XXI, políticas de Ciência, Tecnologia e Inovação (CT\&I) ganharam maior atenção do Estado brasileiro (MATIAS-PEREIRA, 2011). Questões como a formação de redes de pesquisa e a aproximação entre empresas, governos e Institutos de Ciência, Tecnologia e inovação (ICT) passaram a integrar o plano estratégico das instituições que contemplam a inovação tecnológica como pilar adicional aos princípios clássicos da educação - ensino, pesquisa e extensão - intensificado nas universidades públicas brasileiras a partir da Lei n. 10.973, de 2 de dezembro de 2004 (Lei de Inovação), e reforçado pelo Novo Marco legal de Inovação - Lei n. 13.243, de 16 de janeiro de 2016 - e pelo Decreto n. 9.283, de 7 de fevereiro de 2018, que regulamenta as alterações ocorridas na Lei de Inovação (PIRES, 2018).

A produção científica no Brasil tem crescido consideravelmente desde o início dos anos 2000. Em 2016, o país distinguiu-se no ranking das 15 nações com maior volume de produção científica cadastrada na base de dados Scopus, base que disponibiliza o maior número de periódicos científicos de acesso aberto (MARQUES, 2017). Embora o impacto das citações tenha sido historicamente abaixo da média mundial, o Brasil registrou um crescimento de mais de $15 \%$, entre 2010 e 2016 (CLARIVATE ANALYTICS, 2018).

Nesse cenário, destaca-se o crescimento da participação acadêmica referente à proteção de Propriedade Intelectual (PI) e do licenciamento de tecnologias para o seguimento empresarial $e$ industrial. A gestão dessas políticas de PI se caracteriza como um importante instrumento de apoio ao crescimento econômico do país e "[...] se fazem necessárias, especialmente, para as universidades e os centros de pesquisas e para as indústrias, visto que nesse campo ocorre grande parte da criação e inovação tecnológica e cultural." (MATIAS-PEREIRA, 2011, p. 585).

A Universidade Federal do Recôncavo da Bahia (UFRB), criada em 2005, concentra sete Centros de Ensino e Pesquisa, aproximadamente 7.979 alunos de graduação, 583 alunos de pós-graduação e 821 docentes (UNIVERSIDADE FEDERAL DO RECÔNCAVO DA BAHIA, 2017), fundamentando-se como a principal ICT de geração e difusão de conhecimento no interior da Bahia. Em consonância com a política de inovação que rege, entre outras diretrizes a proteção desse conhecimento, criou-se em 2007 o Núcleo de Inovação Tecnológica (NIT) da UFRB, ligado à Pró-Reitoria de Pesquisa e à Pós-Graduação, Criação e Inovação (PPGCI). O NIT/UFRB foi denominado Coordenação de Criação e Inovação (CINOVA) e tem como finalidade gerir a política de inovação institucional, proteger a capacidade criativa de seus pesquisadores e de pesquisadores independentes, além de estimular a aproximação da universidade e empresas (SANTOS et al., 2013).

Após 13 anos de existência da UFRB, foram publicados pelos seus pesquisadores 1.200 artigos na base de dados Web of Science, uma interface que reúne informações sobre artigos publicados em mais de 8.400 periódicos especializados em várias áreas do conhecimento. Em 2008, foram publicados 45 artigos, que, em 2017, somaram 165 artigos, representando um crescimento percentual de $267 \%$ em um período de nove anos.

Em relação ao crescimento de depósito de patentes realizado na UFRB, os números foram bem mais modestos quando comparados aos das publicações, fato este devido à pouca disseminação da "cultura da inovação" entre a comunidade acadêmica, assim como ocorre na maioria das ICTs brasileiras (PIRES, 2018). Em 2008, foi feito o primeiro depósito de patente da UFRB 
e esse número cresceu para nove depósitos em 2013. A baixa adesão ao hábito de registro de ideias e ou de processos inovadores deve-se, ainda, à fragilidade do chamado Sistema Local de Inovação (SLI), que, embora tenha avançado, em 2017 foi registrado um total de 33 depósitos de patente; mesmo após incremento nas políticas de divulgação e conscientização sobre a importância da PI no âmbito acadêmico e como fator competitivo para a economia do país (PIRES; QUINTELLA, 2015).

$\mathrm{Na}$ UFRB verificou-se que, apesar do empenho em estabelecer e em promover uma política de inovação, é preciso considerar que essa política ainda não se consolidou, necessitando de planejamento e estratégias para permitir a promoção de uma política mais efetiva que possa ampliar a interação da universidade com a indústria, o governo e com outras ICTs (PIRES; QUINTELLA, 2015).

Entre os grupos de pesquisa da UFRB cadastrados no CNPq que obtiveram destaque na área de inovação tecnológica com geração de depósitos de patentes, destaca-se o grupo "Bioprodutos e Processos Aplicados à Nutrição Humana" (BIONUTRI) (http://dgp.cnpq.br/ dgp/espelhogrupo/5530056192615998), que registrou 23 depósitos, em sua maioria bebidas e alimentos funcionais direcionados a compostos bioativos, como probióticos e/ou flavonoides.

Embora os pesquisadores do grupo tenham uma formação mais sólida quanto à relação com o segmento privado industrial, eles conhecem a importância das patentes e buscam continuamente a melhoria e o desenvolvimento de novos produtos, existe ainda uma grande dificuldade para tornar tais patentes produtos presentes no mercado, mesmo que esses produtos tenham sido comprovadamente superiores àqueles identificados no mercado consumidor. Essa dificuldade em encontrar caminhos institucionais ou empresas potencialmente interessadas em desenvolver produtos ou processos inovadores já patenteados, por meio de parcerias tecnológicas empresa-academia, é comum para a grande maioria das ICTs brasileiras (QUINTELLA et al., 2018).

Considerando essa lacuna, criou-se em março 2018 o Núcleo de Transferência de Tecnologia e Captação de Recursos (NTT) na CINOVA/UFRB com intuito de prospectar, aproximar e desenvolver o tipo mais adequado de aliança estratégica entre os dois atores principais dessa engrenagem tecnológica: comunidade acadêmica com perfil empreendedor e empresas ávidas por melhorias nos seus gargalos tecnológicos (KLOTZLE, 2002).

A transferência de tecnologia universidade-empresa (TTUE) vem adquirindo importância estratégica cada vez maior em muitos países, pois representa fonte de recursos para a pesquisa acadêmica, inovação para as empresas e desenvolvimento econômico para os governos (CLOSS et al., 2012).

Como o BIONUTRI é detentor de um grande número de produtos inovadores para o crescente mercado de alimentos funcionais, pesquisadores se aliaram e selecionaram um produto já patenteado para exercitar a preparação e o amadurecimento mercadológico até que este possa atingir a fase comercial e servir de modelo para atrair potenciais investidores.

Para tal, foram traçados alguns planos de ação mimetizando as prioridades estratégicas que compõem o lançamento de um produto no mercado. Tais planos foram pautados nos princípios básicos administrativos e organizacionais aplicáveis a qualquer área ou setor no qual se deseja empreender com sucesso, elaborando estratégias que resultem no cumprimento de metas e de objetivos preestabelecidos, e as diretrizes traçadas pelo grupo gestor do projeto e/ou empreendimento (TEIXEIRA; ALONSO, 2014; KALAKI; NEVES, 2017). 
O objetivo deste artigo é apresentar um relato de experiência da utilização de estratégias para transformar uma tecnologia desenvolvida pela academia em uma inovação mercadológica. Trata-se de um processo ainda não finalizado, mas que se caracteriza como um relato importante para estimular outros pesquisadores e profissionais de transferência de tecnologia no tracejo de um caminho viável de transferência de tecnologia e de interação Universidade-Empresa (UE). Optou-se por uma bebida probiótica à base de kefir crescido em extrato de soja que foi desenvolvida, caracterizada e devidamente depositada no Instituto Nacional de Propriedade Industrial (INPI) sob o número BR1020170103943 e publicada na revista Food Science and Technology (DOI: httpI://dx.doi.org/10.1590/1678-457X.10617).

\section{Metodologia}

O presente estudo trata do relato de experiência das estratégias que estão sendo desenvolvidas na UFRB para facilitar o processo de transferência de tecnologias acadêmicas para organizações atuantes no mercado. Com objetivo exploratório e descritivo, esse relato de experiência é apresentado a partir da atuação do NTT da UFRB para executar seu papel de promover e de transferir as tecnologias desenvolvidas por pesquisadores da universidade.

Entre os 33 pedidos de patente requeridos pela UFRB até o ano de 2017, a tecnologia referente a uma bebida probiótica à base de kefir crescido em extrato de soja está sendo utilizada como um caso específico para traçar um caminho favorável para a concretização da transferência de tecnologia, de modo que, ao final do processo, espera-se ter um fluxo referente à transferência de tecnologia que possa ser adequadamente utilizada em outras demandas do NTT.

Os dados analisados são decorrentes da descrição do processo adotado para desenvolver a tecnologia estudada, tornando-o factível e aplicável em um cenário acadêmico semelhante. Adicionalmente, são descritas ações executadas pelo NTT para auxiliar os pesquisadores envolvidos no desenvolvimento da tecnologia, a fim de aumentar a sua maturidade tecnológica e prospectar parceiros interessados na sua comercialização. Em paralelo, faz-se uma correlação teórica com a literatura científica vigente sobre as ações estratégicas que podem ser adotadas para ascender ao mercado um produto inovador com potencial mercadológico.

\section{Resultados e Discussão}

O ponto de partida para o relato deste caso foi o processo seletivo entre os produtos patenteados pelo BIONUTRI para que, ao final, fosse eleita uma bebida probiótica à base de extratos vegetais. No entanto, sob a perspectiva do NTT, outros fatores compuseram a proposta de prospecção comercial antes de selecionar um produto. Para tal, pode-se identificar alguns critérios importantes

\subsection{Perfil do BIONUTRI e Identificação do Produto Patenteado que Melhor Representa a Capacidade Técnica dos Pesquisadores}

Três fatores transmitiram ao NTT a segurança na capacidade técnica do BIONUTRI ao lançar o desafio posto neste relato de caso: 1) a produtividade acadêmica, artigos e citações que 
expressam a capacidade científica do grupo de transformar achados laboratoriais em informações relevantes para a comunidade científica, disponibilizando-as em bases de dados nacionais e internacionais; 2) a produtividade tecnológica (patentes depositadas) de bebidas com apelo funcional (bebidas à base de probióticos, flavonoides, probióticos) com potencial para aprimoramento técnico e/ou criação de novos produtos sintonizados com as necessidades, tendências ou exigências do mercado consumidor; 3) a experiência prévia ou atual dos pesquisadores principais do grupo em lidar com o ambiente empresarial, industrial e acadêmico ao longo de suas vidas profissionais (ex-colaborador, ex-sócio, consultor, etc.), e a cultura empreendedora dos integrantes do grupo.

Além dos fatores expostos, o BIONUTRI conseguiu ao longo dos anos, por meio de ações interativas de abrangência popular com o respaldo institucional da UFRB, divulgar e popularizar o uso caseiro do kefir lácteo como uma prática saudável nas comunidades locais. Tais ações facilitam a potencial e futura aceitação de uma bebida funcional produzida pelo grupo.

\subsection{Maturidade Tecnológica do Produto Selecionado}

A tecnologia, desde o momento em que é criada ou conceitualizada, necessita passar por diversas etapas de evolução, até a sua plena operação, de modo que esteja pronta para o uso ou para a comercialização. O Nível de Maturidade da Tecnologia (NMT) é uma sistemática métrica, com nove etapas, desenvolvida pela National Aeronautics and Space Administration (NASA) em 1974. Permite ordenar as novas tecnologias, com os objetivos fundamentais de possibilitar a comparação com outras e de facilitar o entendimento sobre o estágio atual de desenvolvimento, além de sustentar decisões de fomento de recursos para a inovação e aquelas decisões relacionadas à transição da tecnologia (VELHO et al., 2017). As nove etapas que podem ser aplicadas para análise do grau de maturidade de tecnologias pertencentes a diversos segmentos de inovação são ilustradas na Figura 1.

Figura 1 - Graus de maturidade tecnológica aplicáveis a diversos tipos de inovações

\begin{tabular}{|c|c|c|c|c|c|c|c|c|}
\hline NMT 1 & NMT 2 & NMT 3 & NMT 4 & NMT 5 & NMT 6 & NMT 7 & NMT 8 & NMT 9 \\
\hline 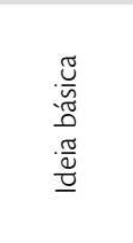 & 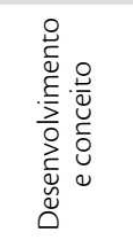 & 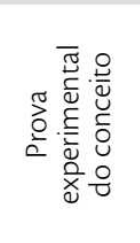 & 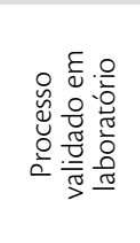 & 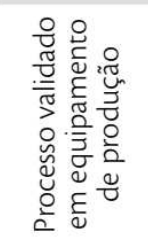 & 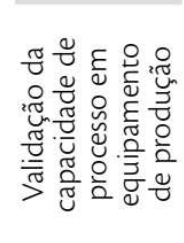 & 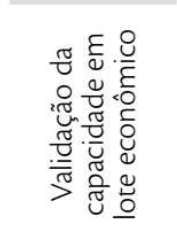 &  & 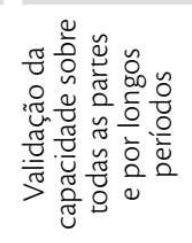 \\
\hline \multirow{2}{*}{\multicolumn{2}{|c|}{ Pesquisa básica }} & \multirow{2}{*}{\multicolumn{2}{|c|}{$\begin{array}{l}\text { Pesquisa } \\
\text { pré-clínica }\end{array}$}} & & FASE 1 & FASE 2 & FASE 3 & FASE 4 \\
\hline & & & & $\begin{array}{l}\text { Pesquisa } \\
\text { pré-clínica } \\
\text { tardia. }\end{array}$ & 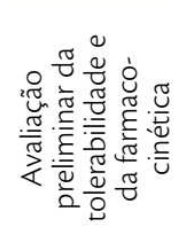 & 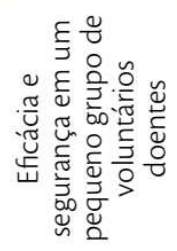 & 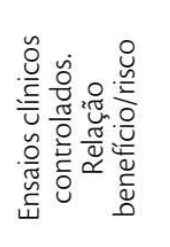 & 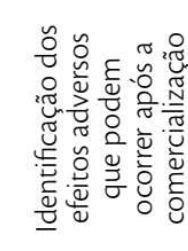 \\
\hline
\end{tabular}

Fonte: Velho et al. (2017)

Para a análise da bebida probiótica à base de kefir crescido em extrato de soja, foi utilizado como referencial teórico os graus de maturidade tecnológica, descritos por Mankins (2009), que, embora também descreva nove diferentes estágios, introduz uma interpretação mais generalista 
que torna a classificação do produto mais coerente com as etapas já cumpridas por ele. De acordo com Mankins (2009), até o presente momento o produto encontra-se em estágio 5 de desenvolvimento, correspondente às seguintes etapas cumpridas:

a) Ideia ou hipótese conceitual, busca de anterioridade em base de patentes (NMT1).

b) Desenvolvimento de produtos e estabilidade da formulação (NMT2).

c) Aspectos analíticos e funcionais da prova de conceito desenvolvida. Análises físico-químicas e microbiológicas necessárias para o registro em órgãos reguladores competentes (NMT3).

d)Desenvolvimento tecnológico do produto em laboratório - processo produtivo, potenciais gargalos tecnológicos, etc. (NMT4).

e) Demonstração da tecnologia pronta em ambiente relevante, extralaboratorial - teste sensorial realizado no Centro de Ciências em Saúde da UFRB para um público de 60 experimentadores (NMT 5).

A partir dessa análise é possível identificar com maior grau de assertividade e clareza os rumos que deverão ser tomados pelo plano estratégico necessário aos próximos passos do ciclo de vida do produto. Velho et al. (2017) afirmam que se destacam como benefícios da análise dos NMTs de um produto os seguintes aspectos:

a) Facilidade de entendimento comum sobre o status atual da tecnologia para uma determinada aplicação.

b)Comparação de tecnologias em seus estágios atuais (instantâneo).

c) Gerenciamento de riscos.

d) Tomada de decisões relacionadas ao financiamento da tecnologia.

e) Tomada de decisões relacionadas à transição da tecnologia.

f) Avaliação métrica da maturidade do programa de tecnologias de projetos, antes que o seu desenvolvimento se inicie.

Mankins (2009) alerta que existem basicamente três grandes desafios frente aos sistemas desenvolvimentais que permeiam este ou qualquer outro projeto de inovação: desempenho no cumprimento das etapas do projeto; execução do cronograma, conforme planejado; e administração do orçamento e/ou financiamento do projeto. Logo, para avançar no grau de maturidade tecnológica do produto em questão, de modo a conduzi-lo ao mercado via alguma modalidade de Transferência de Tecnologia (TT), é necessário que o gestor tenha em mãos avaliações claras e bem documentadas para cada etapa dos NMTs vindouros (MANKINS, 2009).

Com tais informações, o BIONUTRI e o NTT seguiram para identificar o cenário do mercado de bebidas em que o produto selecionado estava inserido.

\subsection{Estudo do Cenário do Mercado de Bebidas Funcionais não Lácteas com Potencial Local, Regional, Nacional e Internacional}

A tarefa do estudo de mercado consiste em avaliar as necessidades de informações de uma organização, de um produto, de um projeto e, assim por diante, de modo a fornecer aos gestores 
informações relevantes, precisas, confiáveis, validas e atuais que, sobretudo, represente uma fonte segura de auxílio à tomada de decisão. Dessa maneira, pode-se dizer, em síntese, que a pesquisa de marketing é a identificação, a coleta (processo de obtenção de dados), a análise (exame, diagnóstico) e a disseminação (derramamento) de informações de forma sistemática (ordenada) e objetiva (prática), e seu uso visa a melhorar a tomada de decisões relacionadas à identificação e à solução de problemas (e oportunidades) em marketing (MALHOTRA, 2012).

A pesquisa de marketing é uma ferramenta que aproxima o consumidor real ou potencial do indivíduo que a utiliza, usando de informações qualitativas ou quantitativas para traçar perfis, preferências, gostos, necessidades, receios, entre outras especificações (MATTAR; OLIVEIRA; MOTTA, 2014).

Neste estudo foi realizada uma busca exploratória, conduzida por meio de levantamento bibliográfico, com palavras-chaves em inglês e em português, digitadas no Google de modo que contemplasse os níveis de abrangência ao qual o BIONUTRI almeja alcançar com a bebida selecionada. Esse aspecto de abrangência mercadológica do produto está também relacionado ao tipo e/ou validade da patente depositada do produto junto ao Instituto Nacional de Propriedade Industrial (INPI).

As palavras-chave adotadas na busca exploratória foram baseadas inicialmente naquelas utilizadas no artigo da bebida patenteada, no entanto, cruzadas com informações e/ou perguntas relevantes para responder a questões sobre a vida comercial dessa categoria de produto, por exemplo:

a)Palavras-chave do artigo: Probiotic, fermentation, food intolerances, vegetarianismo.

b)Palavras-chave identificadas como importantes: Vegetable drinks, functional beverages, Cereal-Based Probiotic Beverages, Non dairy probiotic beverages.

c) Palavras-chave iniciais de cunho mercadológico cruzadas: Market share, Market trends, Consumer preference, quality attributes, global rank.

Conforme apontado por Silva (2018), as técnicas de planejamento estratégico, como Análise SWOT (Strengths, Weakness, Opportunities and Threat); Matriz BCG (Boston Consulting Group); Cinco Forças de Porter (número de concorrentes e repartição de quotas de mercado; taxa de crescimento da indústria; diversidade de concorrentes; complexidade e assimetria informacional; grau de diferenciação dos produtos; e as barreiras à saída); Análise Ambiental e; Time Bound (Estudo do Tempo), podem ser aprendidas em curtas capacitações oferecidas pelo Serviço Brasileiro de apoio às Micro e Pequenas Empresas (SEBRAE) e que podem ser usadas para construção das metas a serem alcançadas pelo BIONUTRI a partir das informações coletadas na busca exploratória.

No presente estudo de caso utilizou-se a análise SWOT que serviu para apresentar de forma direta e resumida o cenário mercadológico do produto que se desejava conhecer, indicando se as oportunidades aliadas às forças sobrepõem e justificam as ameaças e as fraquezas. A análise SWOT é uma ferramenta clássica de autoconhecimento (nesse caso, o conhecimento mais aprofundado a respeito do futuro empreendimento - produção da bebida por uma Startup incubada na UFRB, por exemplo), análise contextual e guia para a definição de um plano de ação. Os pontos fortes e fracos, em geral, estão dentro da própria empresa, enquanto as oportunidades $e$ as ameaças, na maioria dos casos, têm origem externa. O uso da ferramenta Análise SWOT 
é razoavelmente simples. O mais difícil é identificar os reais pontos fortes e fracos da empresa, as oportunidades mais vantajosas e as ameaças mais importantes do ambiente competitivo em que o negócio irá se enquadrar.

A partir da Análise SWOT, somada às informações levantadas pela busca exploratória, o BIONUTRI conseguiu identificar os pontos fortes e fracos do produto selecionado, além das oportunidades no mercado local, regional e nacional e, finalmente, as ameaças à sustentabilidade do potencial empreendimento (criação de uma empresa incubada que produza esse tipo de bebida ou preste esse serviço às empresas do ramo).

Conforme apontado por Raimundo, Batalha e Torkomian (2017), além do uso de alguma técnica mercadológica, é importante identificar alguns pontos que perpassam os seguintes aspectos:

a) Quais as fontes de informações mais relevantes e confiáveis sobre os aspectos mercadológicos do produto?

Feiras/Exposições, Universidades e Institutos de pesquisa, Consumidores e concorrentes, Redes informatizadas, Revistas especializadas, etc.

b) Quais as relações de cooperação mais relevantes para a validação, aceitação e valorização do produto no mercado?

Institutos de ensaios testes e certificações, Centros de capacitação, empresas de consultoria, Feiras/Exposições, Universidades e Institutos de pesquisa, Consumidores, fornecedores, etc.

c) Quais os métodos de proteção de produtos mais utilizados pelas empresas do segmento? Marcas, Patentes, segredo industrial, tempo de liderança sobre outros produtos do mercado, etc.

Após a realização desse "exercício" de viabilidade mercadológica do produto selecionado pelo BIONUTRI, conclui-se que uma parceria (contratação por remuneração, contrato de risco por participação nos resultados) com empresas privadas, juniores ou com consultores independentes poderia otimizar, enriquecer e profissionalizar ainda mais essa etapa específica do projeto. Daí, partiu-se para um levantamento do ambiente empresarial e empreendedor em torno da UFRB (local e regional) que pudesse contribuir com o projeto, empoderando-o e tornando-o ainda mais factível.

\subsection{Análise do Macro e Microambiente Empreendedor Local para Compor a Tomada Decisão de Empreender com a Bebida Patenteada}

O estudo do empreendedorismo tem atraído maior interesse nos últimos anos, principalmente em virtude da sua forte relação com o desenvolvimento regional. Com intuito de promover o comportamento empreendedor, unem-se governos, instituições de ensino e afins investindo esforços e grandes quantidades de recursos financeiros. Além do empenho no desenvolvimento do perfil empreendedor, com foco no indivíduo, mecanismos de suporte à empresa nascente são colocados à disposição de quem deseja abrir seu próprio negócio. Esses mecanismos abrangem desde linhas de crédito $e$ incubadoras tecnológicas até consultorias subsidiadas e eventos para a promoção de redes de negócios (SCHMIDT; BOHNENBERGER, 2009). 
O ambiente de marketing é formado por seis ambientes: demográfico, econômico, natural, tecnológico, político-legal e sociocultural. Esses ambientes contêm forças que podem produzir um impacto importante sobre os participantes do ambiente de marketing. O microambiente de marketing ou ambiente-tarefa é representado pelos fornecedores, intermediários, concorrentes e o mercado do empreendimento em que se deseja empreender e o macroambiente são formados pelo conjunto dos ambientes demográfico, econômico, natural, tecnológico, político legal e sociocultural (KOTLER, 2012).

Esses conceitos básicos, extraídos dos campos de estudo da Administração Estratégica e do Marketing, são aqui resgatados e apresentados para que possam, em última análise, contribuir para o aperfeiçoamento das propostas de um Plano de Negócios (PN). Este, por sua vez, é um documento-mestre fundamental, usado para descrever um empreendimento e um modelo de negócios que sustentam o projeto e/ou um empreendimento qualquer. Sua elaboração envolve um processo de aprendizado e de autoconhecimento e, ainda, permite situar-se no seu ambiente de negócios. O PN é uma ferramenta que se aplica tanto ao lançamento de novos empreendimentos quanto ao planejamento de empresas maduras (SEITZ, 2005; OLIVEIRA, 2017).

Definidos os parâmetros de todo o processo envolvido nesta etapa do ciclo de vida do produto e para que se possa levar a bom termo os objetivos deste estudo de caso, torna-se necessária a escolha e a definição do processo de Planejamento Estratégico de Marketing (Visão, Valores, Missão), suas respectivas etapas (análise SWOT, por exemplo), as estratégias competitivas que serão utilizadas como modelo no desenvolvimento do PN, reforçando seu vínculo com seus respectivos mercados identificados (SEITZ, 2005).

Trazendo esses conceitos descritos por Seitz (2005) para o contexto em torno da bebida probiótica à base de kefir crescido em extrato de soja e objetivando analisar, compreender e prospectar os mercados local (Santo Antônio de Jesus) e/ou regional (estado da Bahia), partiu-se para a elaboração de uma matriz de análise situacional (Quadro 1).

Quadro 1 - Análise situacional do ambiente de marketing em Santo Antônio de Jesus - Bahia

\begin{tabular}{|c|c|c|}
\hline SITUAÇÃO INTERNA* & \multicolumn{2}{|c|}{ SITUAÇÃo EXTERNA** } \\
\hline Ambiente Organizacional & Microambiente & Macroambiente \\
\hline \multirow{6}{*}{$\begin{array}{l}\text { Avalia as capacitaçães mercadológicas e } \\
\text { competitivas da organização, destacando-se: } \\
\text { 1. Produto ou serviço: descrição, finalidades, qualidade, } \\
\text { apoio complementar, vantagens que oferece inovação. } \\
\text { 2. Políticas de Marketing vigentes: produto, } \\
\text { preço, promoção (comunicação integrada de } \\
\text { marketing), distribuição e logística. } \\
\text { 3. Resultados alcançados: evolução das } \\
\text { vendas, reputação da empresa, participação de } \\
\text { mercado, satisfação e retenção de clientes. } \\
\text { 4. Fatores referentes a custo, lucro e indicadores } \\
\text { de desempenho: margem de contribuição, } \\
\text { análise do ponto de equilibrio, indicadores de } \\
\text { relação entre recursos empregados e retorno. }\end{array}$} & $\begin{array}{l}\text { Fornecedores } \\
\text { ( ) Acesso } \\
\text { ( ) Não acessíveis }\end{array}$ & $\begin{array}{l}\text { Ambiente demográfico } \\
\text { ( ) Favorável ao produto } \\
\text { ( ) Desfavorável }\end{array}$ \\
\hline & $\begin{array}{l}\text { Intermediários } \\
\text { ( ) Boa rede } \\
\text { ( ) Não acessíveis }\end{array}$ & $\begin{array}{l}\text { Ambiente econômico } \\
\text { ( ) Favorável ao produto } \\
\text { ( ) Desfavorável }\end{array}$ \\
\hline & $\begin{array}{l}\text { Concorrência } \\
\text { ( ) Presente } \\
\text { () Ausente }\end{array}$ & $\begin{array}{l}\text { Ambiente natural } \\
\text { ( ) Favorável ao produto } \\
\text { () Desfavorável }\end{array}$ \\
\hline & $\begin{array}{l}\text { Consumidores } \\
\text { ( ) Presente } \\
\text { ( ) Ausente }\end{array}$ & $\begin{array}{l}\text { Ambiente tecnológico } \\
\text { ( ) Favorável ao produto } \\
\text { ( ) Desfavorável }\end{array}$ \\
\hline & $\begin{array}{l}\text { Influenciadores } \\
\text { ( ) Presentes } \\
\text { ( ) Ausentes }\end{array}$ & $\begin{array}{l}\text { Ambiente político legal } \\
\text { () Favorável ao produto } \\
\text { () Desfavorável }\end{array}$ \\
\hline & $\begin{array}{l}\text { Ações de Marketing } \\
\text { () Presentes } \\
\text { ( ) Ausentes }\end{array}$ & $\begin{array}{l}\text { Ambiente sociocultural } \\
\text { ( ) Favorável ao produto } \\
\text { ( ) Desfavorável }\end{array}$ \\
\hline
\end{tabular}

* variáveis controláveis, ** variáveis incontroláveis.

Fonte: Adaptado de Seitz (2005) 
Baseado nessa matriz foi possível identificar os atores locais importantes para ações de prospecção, divulgação do NTT, objetivando não somente a aproximação da comunidade acadêmica UFRB com as empresas da região, mas também maximizando as chances de captação de recursos via parceiros investidores.

Os possíveis e potenciais atores que compõem o micro e macroambiente empreendedor identificados na região e que foram abordados até o momento são:

\subsubsection{Associação Comercial e Empresarial da Cidade de Santo Antônio de Jesus}

Santo Antônio de Jesus é considerado o município mais importante do Recôncavo Baiano pela sua importância como centro comercial, industrial e de serviços de toda a região. Segundo o Instituto Brasileiro de Geografia e Estatística (2018), o município contava em 2017 com população estimada de mais de 103 mil habitantes e Produto Interno Bruto per capita de $\mathrm{R} \$ 18.539,00$, ficando em $32^{\circ}$ lugar entre 417 municípios baianos.

Baseado nesse contexto, a Associação Comercial e Empresarial de Santo Antônio de Jesus (ACESAJ) exerce um papel fundamental no micro e no macroambiente de marketing no qual o produto está inserido. Adicionalmente, a Acesaj trabalha em parceria estrategicamente articulada com a Câmara de Diretores Lojistas (CDL), Sindicato do Comércio (SINCOMSAJ) e o Sebrae local, atores fundamentais para a inserção e as demais etapas do ciclo de vida do produto. Além disso, os potenciais investidores locais ocupam cadeiras nessas associações.

O NTT cumprindo um dos seus papéis institucionais de atuar com a TTUE visitou e apresentou as possibilidades de negócio baseado na produtividade de três grupos de pesquisa $e$ seis pesquisadores. Durante a apresentação foi realizada uma degustação de um dos produtos apresentados e abriram-se possibilidades até então inéditas para o empresariado local. A Acesaj convidou o NTT a apresentar aquilo que classificou como "oportunidades de negócio" sempre que desejarem, já que a cidade vive um dilema econômico por não investir em novas ideias (produtos ou processos), mas sim reproduzir o cotidiano comercial da compra/venda. Após a apresentação, houve uma grande repercussão entre os empresários, gerando inclusive uma demanda relativa à busca de pesquisadores ligados ao setor de máquinas de produção e beneficiamento de chocolate.

\subsubsection{Empresas Juniores das ICTs Público e Privadas da Região}

Em busca de mão de obra especializada que desse respaldo técnico para construir avaliações como pesquisas de mercado, planejamentos estratégicos de marketing e planos de negócios, alavancando, assim, o projeto "bebida funcional" patenteada pelo BIONUTRI, iniciou-se um levantamento do "status" do ecossistema de inovação da região.

O termo criado em 1993 por James Moore, nomeadamente ecossistema de negócio, baseou-se em um tipo de concentração geográfica de empreendedores, investidores, talentos, universidades que engloba todos os indivíduos, organizações, entidades governamentais, com 
os quais uma empresa interage, incluindo os consumidores, competidores e outros agentes. A função de um ecossistema líder é possibilitar os membros da comunidade de dividirem ideias para alinhar seus investimentos e encontrar modos de apoio mútuo, desde que o sucesso da continuidade do ecossistema esteja no fato de criar uma rede de relacionamentos que se recompensam de forma mútua. Isso se realiza, pois cada líder de um ecossistema estabelece uma capacidade central que se torna a base para criação de valores e de consumidores, por meio da combinação de agentes e de colaboradores envolvidos (KON, 2016).

Resumidamente, o ecossistema de inovação em Santo Antônio de Jesus seria composto de uma rede entre as universidades públicas ou privadas locais, os centros de pesquisa regionais, as empresas já estabelecidas, empresas Startup incubadas ou não, fundos financiadores e as linhas de apoio governamental.

Embora não exista localmente tamanha estrutura, partiu-se daquilo que a cidade de Santo Antônio de Jesus pode oferecer, buscando valorizar os atores, contratando seus serviços e estimulando-os a construir um "microecossistema" local para incentivar a cultura da inovação.

A cidade possui cinco Instituições de Ensino Superior, sendo que alguma delas hospeda suas próprias empresas juniores, são elas:

a) UFRB, Centro de Ciências Exatas e Tecnológicas (CETEC).

b) Universidade do Estado da Baia (UNEB), Departamento de Ciências Humanas (DCH), Campus V.

c) Faculdade de Ciências e Empreendedorismo (FACEMP).

d) Universidade de Salvador (UNIFACS).

e) Instituto Federal da Bahia (IFBA).

Após busca e visita pessoal a algumas das ICTs, constatou-se a possibilidade de contratação do serviço de elaboração de um PN pela Facemp e contratou-se o serviço de pesquisa de preferência do consumidor pela Empresa Junior da UNEB.

Após a apresentação da proposta e a pactuação das condições gerais de pagamento, construiu-se a "quatro mãos" os pontos a serem abordados na pesquisa de opinião e estabeleceu-se uma meta de 200 entrevistados ( $25 \%$ da população-alvo, potencialmente consumidora da bebida funcional em estudo). A Figura 2 apresenta o questionário composto de 11 perguntas. 
Figura 2 - Estrutura de questionário com pesquisa de opinião, elaborado pela empresa júnior contratada pela UNEB

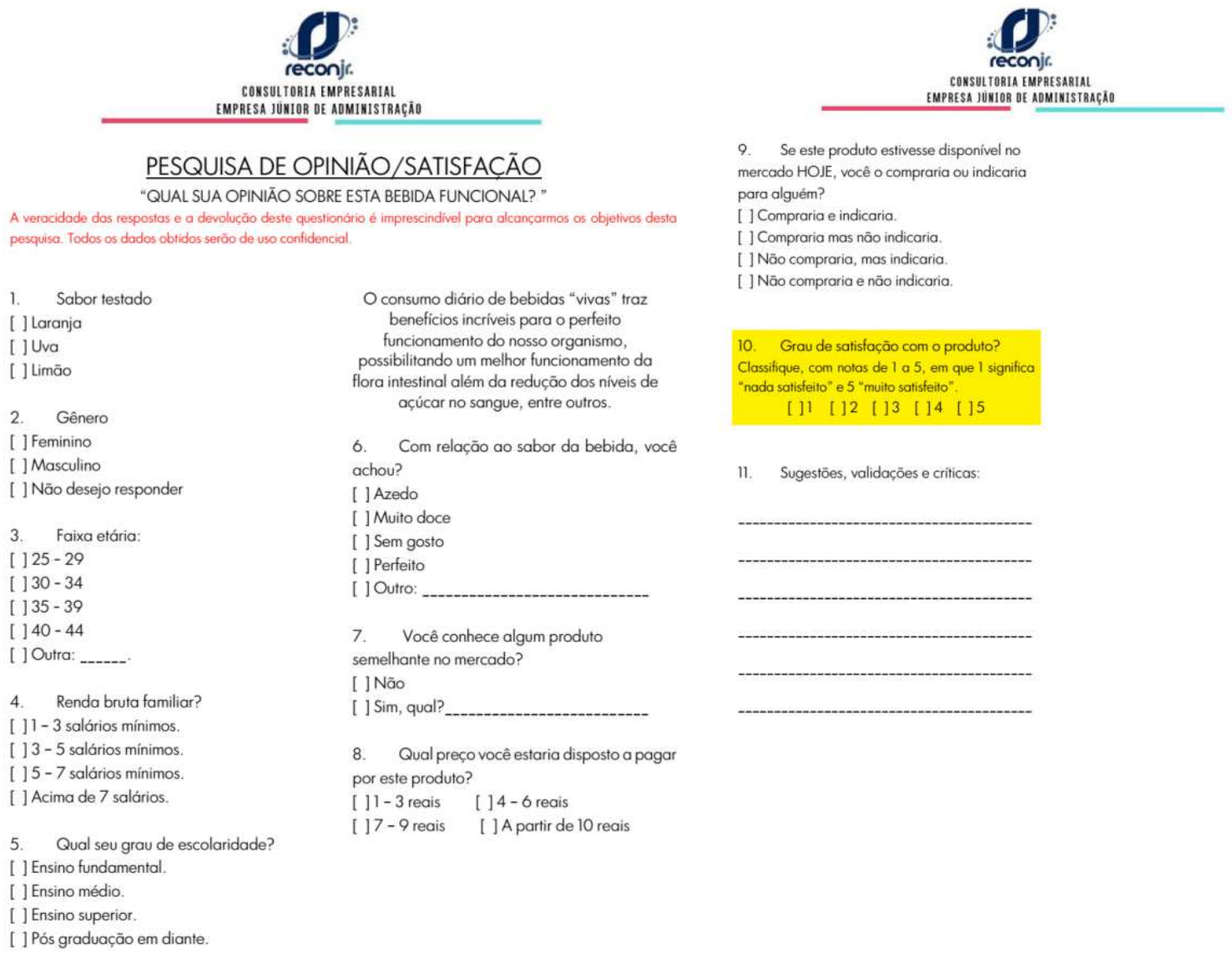

Fonte: Elaborada pelos autores deste artigo (2018)

Outra iniciativa para construir uma potencial rede do "microecossistema de inovação" em Santo Antônio de Jesus foi a contratação dos serviços de análises físico-químicas e microbiológicas por laboratórios sediados na própria UFRB.

Interessante que, ao serem abordados com a proposta de contratação de serviço pelos pesquisadores do BIONUTRI, os docentes admitiram desconhecer os trâmites internos da universidade que garantam o recebimento e o gerenciamento direto do recurso pago em benefício dos seus laboratórios. Alegam ainda que, devido a isso, sentiam-se extremamente desmotivados a estabelecer parcerias de prestação de serviço para terceiros.

Esse foi mais um passo vitorioso dado pela NTT, pois, sem que fosse a intenção, conseguiu-se desmistificar, instruir, incentivar e, finalmente, contratar os serviços de um laboratório de análise da própria UFRB que estava desativado antes de este estudo de caso ser iniciado.

\subsection{Captação de Recursos Versus Alianças Estratégicas}

Além do fomento via editais públicos para produtos inovadores em fase de desenvolvimento, ideias inovadoras ou algo semelhante, o trabalho da busca por captação de recursos dá-se por meio da formação das chamadas Alianças Estratégicas (AE). Entre as várias definições para AE, Teece (1992) elaborou a seguinte: 
Acordos nos quais dois ou mais parceiros dividem o compromisso de alcançar um objetivo comum, unindo todas as suas capacidades e recursos e coordenando as suas atividades. Uma aliança estratégica implica algum grau de coordenação estratégica e operacional das atividades e inclui, entre outras, as seguintes operações: atividades conjuntas de Pesquisa e Desenvolvimento (P\&D), transferência mútua de tecnologia, concessão de direitos exclusivos de produção e venda e acordos de cooperação na área de marketing. Alianças estratégicas podem ou não envolver participação acionária.

No entanto, para alcançar o estágio de uma promissora $\mathrm{AE}$, é desejável que haja o maior grau de maturidade tecnológica possível para o produto, de modo que ele se torne o mais "atraente" para o mercado investidor. As AEs podem assumir diferentes e possíveis formas que dependerão, entre outros fatores, do tipo de pesquisa adotado, do universo e da amostra a ser analisada (KLOTZLE, 2002). A Figura 3 aponta, a partir do que afirmam Teece (1992), Hagedoorn e Narula (1996), Dussauge e Garrette (1995; 1999), Lorange e Roos (1996) e Garai (1999), estes possíveis caminhos:

Figura 3 - Tipos de Alianças Estratégicas

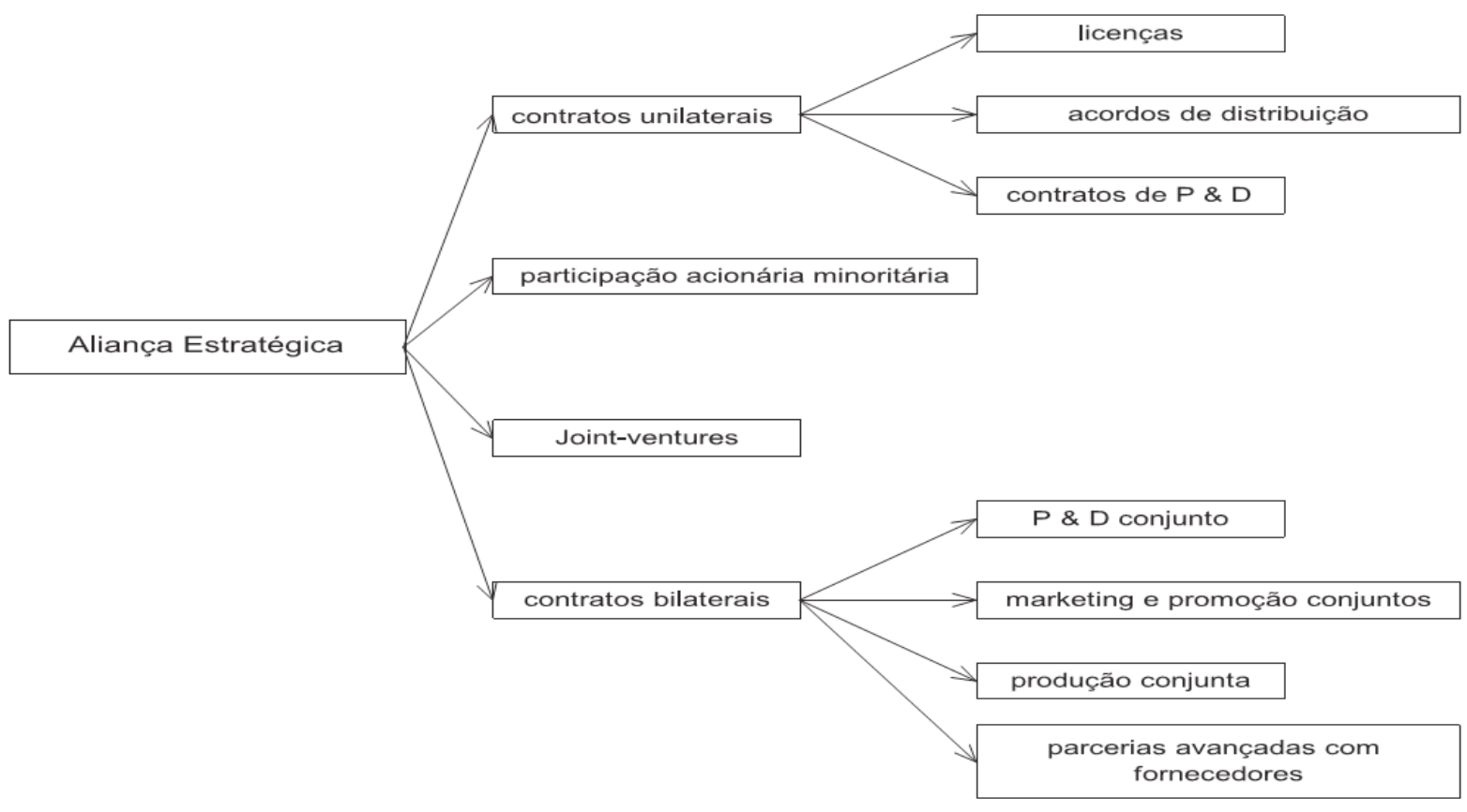

Fonte: Klotzle (2002)

Como o produto do presente relato de caso encontra-se em estágio 5 de desenvolvimento e devido às dificuldades do mencionado microecossistema de inovação regional, buscou-se novas formas de financiamento para o estágio em que o produto se encontra. Daí, os seguintes caminhos estão sendo cogitados:

\subsubsection{Crowdfunding ou Financiamento Colaborativo}

As plataformas de crowdfunding (financiamento coletivo ou financiamento colaborativo) surgem como uma nova alternativa para o auxílio a projetos financiados por pessoas físicas, por trabalhar com um conceito em que pessoas comuns podem financiar um projeto com doações financeiras para o mesmo (SILVA; FREITAS, 2012). O processo para a aprovação de um 
projeto com crowdfunding é complexa e envolve várias etapas, e atores envolvidos para o seu financiamento. É necessária uma visão sistêmica que permita ao realizador conseguir o recurso, visualizando as relações existentes entre as diversas partes envolvidas (MONTEIRO, 2014). O Brasil já ocupa o $17^{\circ}$ lugar entre os países que utilizam esse tipo de captação de recursos para realização de projetos das mais diversas áreas (CROWDFUNDING'S POTENTIAL FOR THE DEVELOPING WORLD, 2013).

\subsubsection{Investidores Locais Independentes (Anjos Investidores)}

Investimento anjo, startups, é aquele que é feito em geral por pessoas físicas que dispõem de parte de seu patrimônio para investir em empresas em estágio inicial, que possua, ou não, uma operação, mas com potencial expressivo de crescimento e de inovação. Geralmente são pessoas com experiência que contribuem não apenas financeiramente, mas também agregam valor ao empreendimento por meio de sua experiência. Investidores anjos adquirem uma participação, em geral, minoritária e não assumem uma posição executiva na empresa. Esse tipo de investimento gira em torno de $\mathrm{R} \$ 50$ mil a $\mathrm{R} \$ 500$ mil, valor que pode ser proveniente de apenas um investidor ou mesmo de um grupo de investidores, prática aconselhável quando se busca reduzir os riscos do investimento, agregando ainda mais experiência e valor ao empreendimento (PERONI; OLIVEIRA, 2015).

Após a apresentação do NTT na Acesaj, surgiram alguns profissionais liberais da cidade (médicos, médicos veterinários, empresários locais) que gostariam de investir em oportunidades de negócio com a chancela da UFRB desde que fosse apresentado um bom PN demonstrando os riscos e os benefícios do investimento. Para esse tipo de parceria ainda não foram encontrados instrumentos legais que possam dar segurança e garantias a ambas as partes. No entanto, considerou-se muito positivo essa demanda já que isso demonstra credibilidade nos projetos que já foram apresentados à comunidade.

\section{Perspectivas e Cenário em TTUE}

O significado do presente estudo de caso mora principalmente no fato de a UFRB representar uma realidade bastante comum comprada a outras ICTs brasileiras no que tange ao campo de TTUE e à captação de recursos para execução de projetos de pesquisa, desenvolvimento $e$ inovação. Mesmo sendo possuidora de uma estrutura organizacional em relação à gestão de seu patrimônio intelectual por meio da CINOVA/UFRB desde 2007, a instituição enfrenta obstáculos, tanto internos (ausência de uma cultura da inovação, entraves burocráticos para atrair parcerias promissoras, falta de estrutura operacional multidisciplinar qualificada, etc.) quanto externos (empresas, centros de pesquisa anjos investidores, prestadores de serviço e consumidores potencialmente ávidos por inovações, ou seja, um ecossistema inovador). Enfrentar esses obstáculos propiciará a consolidação dessa importante etapa do ciclo de vida de um produto/ processo inovador que é a TTUE. Apesar de o tema ser de indiscutível relevância para o desenvolvimento econômico de uma nação, ainda há poucos estudos sobre o assunto em países em desenvolvimento, tanto em instituições públicas quanto privadas (CLOSS et al., 2012).

No Brasil, a Universidade Federal de Minas Gerais (UFMG) está adotando uma estratégia para maximizar seus sucessos no setor de TTUE. A ICT ocupou em 2016 o primeiro lugar no 
ranking das instituições de ensino e pesquisa, depositante de patentes de invenção com um número de 70 depósitos, segundo o Boletim Mensal de Propriedade Industrial do INPI (BRASIL, 2017). No entanto, para além do desafio de gerar tecnologias por meio das pesquisas acadêmicas, está a transferência dessas invenções para o mercado, por meio da interação UE. Por isso, a Coordenadoria de Transferência e Inovação Tecnológica (CTIT) da instituição, após 20 anos de funcionamento, com o intuito de dar maior visibilidade às pesquisas, lançou seu novo portal de inovação, a chamada "Vitrine Tecnológica", que é uma seção em que os interessados encontram as tecnologias da UFMG separadas por área. O resumo executivo e as informações da invenção são disponibilizados em vídeos, no formato de pitches (discurso de venda), com descrição do potencial e das vantagens da tecnologia.

Já a Universidade Estadual de Campinas (UNICAMP), segunda colocada em 2016 no ranking nacional das instituições de ensino e pesquisa depositante de patentes de invenção, com 62 pedidos de patente, possui desde 2003, a Inova - Unicamp, que também se encontra em processo contínuo de amadurecimento, inclusive no que tange à TTUE, conforme apontado por Dias e Porto (2013). Os autores relatam que a escassez de pessoal permanente, o elevado número de pessoal temporário e a inexistência de uma política institucional para regulamentar a criação de empresas spin-offs compõem alguns dos gargalos operacionais do Núcleo (DIAS; PORTO, 2013).

Assim como instituições nacionais renomadas, com décadas de funcionamento na área de gestão de patentes, alguns dos principais obstáculos para o sucesso do NTT da UFRB em relação à TTUE são:

a) Criar uma "cultura" de Propriedade Intelectual e transferência de tecnologia na ICT.

b) Profissionalizar a gestão da transferência dos resultados de pesquisa.

c) Articular as interações e ajustes necessários para a efetivação da transferência de tecnologia (e/ou conhecimento) gerada na ICT.

Outros tópicos importantes em TTUE no Brasil, abordados por Closs et al. (2012), referem-se a fatores motivacionais e desmotivacionais do pesquisador. A falta de recompensa para o professor é um desmotivador para a TTUE, enquanto a possibilidade de obter recursos financeiros, maior interação com o mercado e melhor utilização de equipamentos foram aspectos apontados como motivadores. Com a divulgação e a melhor compreensão da Lei $n$. 13.243/2016, as formas de recompensas ao pesquisador tornaram a busca por parcerias mais interessantes nas relações UE.

Ainda, segundo Closs et al. (2102), entre os principais determinantes para o desempenho da TTUE, estão as políticas institucionais e os procedimentos para o gerenciamento da TT das ICTs. Instituições com regras internas para patenteamento demonstram aos pesquisadores seu empenho em promover uma mudança cultural, em desenvolver um ambiente empreendedor e legitimar essa atividade.

Santana e Porto (2009) argumentam que regras institucionais que tratam dos conflitos de interesses entre as responsabilidades de ensino $e$ as atividades externas dos acadêmicos afetam positiva e significativamente o desempenho universitário em contratos de P\&D e licenciamentos. Devido à carência de regras nesse sentido, no Brasil, há casos de demora e de ausência de envio de relatórios descritivos de patentes por causa da sobrecarga 
de atividades de ensino. Adicionalmente, Closs et al. (2012) relatam que as políticas institucionais de avaliação e de fomento à pesquisa do governo valorizam, quase que exclusivamente, publicações científicas e não a geração de patentes por parte dos pesquisadores.

Embora o estudo de caso esteja ainda em andamento, é visível a mudança de postura dos pesquisadores visitados e/ou contratados para atuar no Projeto. Graças à movimentação em torno do tema, reuniões foram provocadas com diferentes setores da UFRB (financeiro, planejamento, convênios, almoxarifado, etc.) e um grande avanço na curva de aprendizado do grupo pôde ser observado. Como exemplo, cita-se o laboratório de análises que estava desativado por acreditar que não teria como receber os recursos em benefício próprio, imaginando que o pagamento de um serviço para terceiros cairia na conta geral da UFRB e se perderia no orçamento global da instituição. Após apropriação do assunto por parte do NTT e de aproximação do setor administrativo com o laboratório de análises, este já está prestando seu primeiro serviço de análise de água para um cliente externo.

Com a divulgação da inauguração do Núcleo e a visita aos laboratórios de pesquisa dos vários campi da UFRB, em quatro meses de funcionamento já houve espontâneos interesses, até o momento quatro pesquisadores com produtos em diferentes graus de maturidade tecnológica já foram procurados. Embora as etapas trilhadas pertençam a várias áreas de conhecimento, busca-se ajuda dentro da própria universidade e nas instituições parcerias locais e regionais.

\section{Considerações Finais}

Após alguns meses de trabalho, o NTT da CINOVA/UFRB percebeu o vasto universo de conhecimentos multidisciplinares necessários para atuar efetiva e eficazmente com TTUE. É exatamente o tamanho desse desafio que torna tal missão ainda mais motivante. Embora a estrutura operacional (RH, capacitação técnica) esteja longe do ideal, foi possível a identificação de algumas importantes ações iniciais e relativamente simples que podem ser adotadas por qualquer Núcleo iniciante, como: o levantamento do potencial criativo, tecnológico patentário e empreendedor do corpo docente; o mapeamento dos gargalos tecnológicos do ecossistema inovador da região; o perfil e o nível de conhecimento em PD\&I do empresariado local; os entraves institucionais reais ou "construídos" que dificultam a adesão à cultura inovadora; a adesão de empresas juniores como estratégia reversa de aproximação e de divulgação da cultura da inovação entre a comunidade discente; além de outras ações.

Embora muitos outros desafios virão, há a segurança de que o processo de Transferência de Tecnologia Universidade-Empresa represente uma passagem obrigatória no caminho que acompanha o ciclo de vida de uma inovação tecnológica (criação, desenvolvimento, validação, patenteamento, etc.), o que maximiza a chance de instituir a cultura do empreendedorismo científico como forma de levar ao público grandes melhorias nascidas no ambiente acadêmico.

\section{Referências}

BRASIL. Instituto Nacional de Propriedade Industrial (INPI). Diretoria Executiva. Assessoria de Assuntos Econômicos. Indicadores de Propriedade Industrial 2017. Rio de Janeiro: Instituto Nacional de Propriedade Industrial - INPI, 2017. 78p. 
CLARIVATE ANALYTICS. Research in Brazil: a report for Capes by Clarivate Analytics. Clarivate Analytics, 2018. Disponível em: < https://www.capes.gov.br/images/stories/download/ diversos/17012018-CAPES-InCitesReport-Final.pdf>. Acesso em: 7 jul. 2018.

CLOSS, L. et al. Intervenientes na transferência de tecnologia universidade-empresa: o caso PUCRS. RAC-Revista de Administração Contemporânea, [S.l.], v. 16, n. 1, 2012. Disponível em: <http:// www.scielo.br/pdf/rac/v16n1/a05v16n1>. Acesso em: 7 jul. 2018.

CROWDFUNDING'S POTENTIAL FOR THE DEVELOPING WORLD. infoDev, Finance and Private Sector Development Department. Washington, DC: World Bank, 2013. Disponível em: <https:// www.infodev.org/infodev-files/wb_crowdfundingreport-v12.pdf>. Acesso em: 5 jul. 2018.

DIAS, A. A.; PORTO, G. S. Gestão de transferência de tecnologia na inova Unicamp. Revista de Administração Contemporânea, Curitiba, v. 17, n. 3, p. 263-284, jun. 2013. Disponível em: $<$ http://www.scielo.br/scielo.php?script=sci_arttext\&pid=S1415-65552013000300002\&lng=pt\&nrm =iso $>$. Acesso em: 7 jul. 2018.

DUSSAUGE, P.; GARRETT, B. The future of the defence firm: collaboration, co-operation and strategic alliance. In: The future of the defence firm: new challenges, new directions. Springer, Dordrecht, 1995. p. 121-132. Disponível em: <https://ink.springer.com/ chapter/10.1007/978-94-015-8512-5_10>. Acesso em: 8 ago. 2018.

Cooperative strategy: Competing successfully through strategic alliances. Chichester: Wiley, 1999.

GARAI, G. Leveraging the rewards of strategic alliances. Journal of Business Strategy, [S.l.], v. 20, n. 2, p. 40-41, 1999. Disponível em: <https://www.emeraldinsight.com/doi/abs/10.1108/ eb039994?journalCode $=$ jbs $>$. Acesso em: 8 ago. 2018.

INSTITUTO BRASILEIRO DE GEOGRAFIA E ESTATÍSTICA (IBGE). Cidades: Santo Antônio de Jesus-BA. [2018]. Disponível em: <https://cidades.ibge.gov.br/brasil/ba/santo-antonio-de-jesus/ historico >. Acesso em: 8 ago. 2018

HAGEDOORN, J.; NARULA, R. Choosing organizational modes of strategic technology partnering: international and sectoral differences. Journal of International Business Studies, [S.l.], v. 27, n. 2, p. 265-284, 1996. Disponível em: <https://core.ac.uk/download/pdf/6818889.pdf>. Acesso em: 8 ago. 2018

KALAKI, R. B.; NEVES, M. F. Plano estratégico para o sistema agroindustrial citrícola brasileiro. Gestão \& Produção, [S.l.], v. 24, n. 2, p. 338-354, 2017. Disponível em: <www.scielo.br/pdf/ gp/2017nahead/0104-530X-gp-0104-530X1307-15.pdf>. Acesso em: 5 jul. 2018.

KLOTZLE, M. C. Alianças estratégicas: conceito e teoria. Revista de Administração

Contemporânea, [S.l.], v. 6, n. 1, p. 85-104, 2002. Disponível em: <http://www.scielo.br/scielo. php?pid=s1415-65552002000100006\&script=sci_arttext $>$. Acesso em: 5 jul. 2018.

KON, A. Ecossistemas de inovação: a natureza da inovação em serviços. Revista de

Administração, Contabilidade e Economia da Fundace, [S.l.], v. 7, n. 1, 2016. Disponível em: $<$ https://www.fundace.org.br/revistaracef/index.php/racef/article/view/170>. Acesso em: 7 jul., 2018

KOTLER, P. Marketing 3.0. Rio de Janeiro: Elsevier Brasil, 2012.

LORANGE, P.; ROOS, J. Alianças estratégicas: formação, implementação e evolução. São Paulo: Atlas, 1996. 
MALHOTRA, N. K. Pesquisa de marketing: uma orientação aplicada. Porto Alegre: Bookman Editora, 2012.

MANKINS, J. C. Technology readiness assessments: a retrospective. Acta Astronautica, [S.I.], v. 65, n. 9-10, p. 1.216-1.223, 2009. Disponível em: <https://www.sciencedirect.com/science/article/pii/ S0094576509002008>. Acesso em: 20 maio 2018.

MARQUES, F. Produção científica acessível. Revista Pesquisa Fapesp, São Paulo, n. 259, p. 44 -47 , set. 2017.

MATIAS-PEREIRA, J. A gestão do sistema de proteção à propriedade intelectual no Brasil é consistente?. Revista de Administração Pública, [S.l.], v. 2, n. 2, p. 44-74, 2011. Disponível em: $<$ http://bibliotecadigital.fgv.br/ojs/index.php/rap/article/view/7006>. Acesso em: 7 jul. 2018.

MATTAR, F. N.; OLIVEIRA, B.; MOTTA, S. Pesquisa de marketing: metodologia, planejamento, execução e análise. Rio de Janeiro: Elsevier Brasil, 2014.

MONTEIRO, M. C. P. Crowdfunding no Brasil: uma análise sobre as motivações de quem participa. 2014, 209f. Dissertação (Mestrado) - Escola Brasileira de Administração Pública e de Empresas, Centro de Formação Acadêmica e Pesquisa, Brasil, 2014.

OLIVEIRA, M. J. C. P. Empreendedorismo: A importância do plano de negócios para a constituição e desenvolvimento de uma empresa. MBA Gestão de Negócios, Controladoria e Finanças Instituto de Pós-Graduação (IPOG). Revista Especialize On-line IPOG, Goiânia, Ano 8, Edição n. 14, v. 1, dezembro, 2017.

PERONI, B. O.; OLIVEIRA, I. C. Cartilhas de capital empreendedor: investimento anjo. Brasília: Sebrae, 2015

PIRES, E. A. Política de Inovação nas Universidades Brasileiras: Diretrizes para Consolidação dos Núcleos de Inovação Tecnológica. 2018, 189f. Tese (Doutorado) - Universidade Federal de Sergipe, São Cristóvão, Sergipe, 2018.

PIRES, E. A.; QUINTELLA, C. M. Política de Propriedade Intelectual e Transferência de Tecnologia nas Universidades: uma perspectiva do NIT da Universidade Federal do Recôncavo da Bahia.

HOLOS (on-line), [S.1.], v. 6, p. 178-195, dez. 2015. Disponível em: <http://www2.ifrn.edu.br/ojs/ index.php/HOLOS/article/view/3600/1222>. Acesso em: 5 jul. 2018.

QUINTELLA et al. 10 anos da estratégia de estado para consolidação do Sistema Nacional de Inovação Brasileiro: contribuição dos Núcleos de Inovação Tecnológica (NIT). In: SOUZA, E. R. (Org.). Políticas Públicas de Ciência, Tecnologia e Inovação e o Estado Brasileiro. Salvador: EDIFBA, 2018. p. 21-58.

RAIMUNDO, L. M. B.; BATALHA, M. O.; TORKOMIAN, A. L. V. Dinâmica tecnológica da Indústria Brasileira de Alimentos e Bebidas (2000-2011). Gestão \& Produção, São Carlos, v. 24, n. 2, p. 423-436, June, 2017. Disponível em: <http://www.scielo.br/scielo.php?pid=S0104530X2017005009101\&script=sci_abstract\&tlng=pt $>$. Acesso em: 7 jul. 2018.

SANTANA, É. E. P.; PORTO, G. S. E agora, o que fazer com essa tecnologia? Um estudo multicaso sobre as possibilidades de transferência de tecnologia na USP-RP. RAC-Revista de Administração Contemporânea, [S.l.], v. 13, n. 3, 2009. Disponível em: <http://www.scielo.br/pdf/rac/v13n3/ v13n3a05>. Acesso em: 5 jul. 2018.

SANTOS, F. L. et al. Avaliação da política institucional em propriedade intelectual da Universidade Federal do Recôncavo da Bahia. Revista Magistra, [S.I.], v. 25, p. 302-308, 2013. 
SCHMIDT, S.; BOHNENBERGER, M. C. Perfil empreendedor e desempenho organizacional. RACRevista de Administração Contemporânea, [S.l.], v. 13, n. 3, 2009. Disponível em: <http://www. scielo.br/pdf/rac/v13n3/v13n3a07>. Acesso em: 7 jul. 2018.

SEITZ, H. M. O planejamento estratégico de marketing e o plano de negócios. eGesta - Revista Eletrônica de Gestão de Negócios, [S.l.], v. 1, n. 3, p. 91-126, 2005. Disponível em: <http://www. unisantos.br/mestrado/gestao/egesta/artigos/46.pdf> . Acesso em: 7 jul. 2018.

SILVA, A. L. Ferramentas do Planejamento Estratégico: aplicabilidade nas micro e pequenas empresas. Revista de Iniciação Científica da Universidade Vale do Rio Verde, [S.I.], v. 8, n. 1, 2018. Disponível em: <http://periodicos.unincor.br/index.php/iniciacaocientifica/article/view/4316>. Acesso em: 7 jul. 2018.

SILVA, W. S.; FREITAS, J. C. A abordagem sistêmica para o Crowdfunding no Brasil: um estudo exploratório-visão sistêmica dos negócios. In: $8^{\circ}$ CONGRESSO BRASILEIRO DE SISTEMAS.

Revista Gestão \& Conhecimento. Poços de Caldas. 2012. p. 316-334. Disponível em: < https:// www.pucpcaldas.br/graduacao/administracao/revista/artigos/esp1_8cbs/19.pdf $>$. Acesso em: 7 jul. 2018.

TEECE, D. J. Competition, cooperation, and innovation: Organizational arrangements for regimes of rapid technological progress. Journal of Economic Behavior \& Organization, [S.l.], v. 18, n. 1, p. 1-25, 1992. Disponível em: < https://www.sciencedirect.com/science/article/ pii/016726819290050L>. Acesso em: 7 jul. 2018.

TEIXEIRA, C. A.; ALONSO, V. L. C.; A Importância do Planejamento Estratégico para as Pequenas Empresas. In: SIMPÓSIO DE EXCELÊNCIA EM GESTÃO E TECNOLOGIA (SEGET), XI, 2014, Rio de Janeiro, RJ. Anais... Rio de Janeiro, RJ, 2014.

\section{UNIVERSIDADE FEDERAL DO RECÔNCAVO DA BAHIA (UFRB). UFRB em Números.}

[2017]. Disponível em: <https://www.ufrb.edu.br/proplan/ufrb-em-numeros/category/26-ufrb-emnumeros-2017>. Acesso em: 5 jul. 2018.

VELHO, S. R. K. et al. Nível de Maturidade Tecnológica: uma sistemática para ordenar tecnologias. Parcerias Estratégicas, [S.l.], v. 22, n. 45, p. 119-140, jul./dez., Brasília, DF, 2017. Disponível em: <http://seer.cgee.org.br/index.php/parcerias_estrategicas/article/viewFile/867/793>. Acesso em: 7 jul. 2018.

\section{Sobre os autores}

\section{Gustavo Modesto Amorim}

E-mail: gustavomamor@gmail.com

Mestre em Gestão de Tecnologia em Saúde (IMS/UERJ). Especialista em Farmácia Clínica (Univ. Santiago do Chile). Especialista Alopata Magistral (ANFARMAG). Especialista Homeopata (IHB).

Endereço Profissional: Pró-Reitoria de Pesquisa, Pós-Graduação, Criação e Inovação, Universidade Federal do Recôncavo da Bahia, Rua Rui Barbosa, n. 7.410, Centro, Cruz das Almas, BA. CEP: 44380-000. 


\section{Edilson Araújo Pires}

E-mail: edilson@ufrb.edu.br

Doutor e Mestre em Ciência da Propriedade Intelectual pela Universidade Federal de Sergipe (UFS), Especialização em Psicopedagogia (FAZAG).

Endereço profissional: Pró-Reitoria de Pesquisa, Pós-Graduação, Criação e Inovação, Universidade Federal do Recôncavo da Bahia, Rua Rui Barbosa, n. 7.410, Centro, Cruz das Almas, BA. CEP: 44380-000.

\section{Ferlando Lima Santos}

E-mail: ferlandolima@yahoo.com.br Doutor e Mestre em Ciência e Tecnologia de Alimentos pela UFV. Graduado em Nutrição pela UFBA.

Endereço profissional: Centro de Ciências da Saúde, Universidade Federal do Recôncavo da Bahia, Avenida Carlos Amaral, n. 1.015, Cajueiro, Santo Antônio de Jesus, BA. CEP: 44574-490. 